\title{
LA EXCUSA ABSOLUTORIA FAMILIAR EN LOS DELITOS PATRIMONIALES Y LA IMPOSIBILIDAD DE ACCIÓN PENAL ENTRE PARIENTES
}

\author{
Jacinto Pérez Arias ${ }^{1}$ \\ Doctor en Derecho \\ Universidad de Murcia \\ E-mail: jacintoperez@um.es
}

\begin{abstract}
RESUMEN: En el derecho penal español es bien conocido que existe una excusa absolutoria en los delitos patrimoniales, cuando los autores o partícipes de tales conductas tengan vínculo familiar con las víctimas. Excusa que desde la jurisprudencia se convierte en una cláusula general de exención de responsabilidad penal, a partir de lo establecido en la Ley de Enjuiciamiento Criminal. Sin embargo, la existencia de aquella singular excepción de responsabilidad en materia penal patrimonial permite interpretar que la excusa general establecida en la Ley procesal se encuentra totalmente desprovista de vigencia jurídica, dada la enorme contradicción existente entre ellas, a pesar de su coincidencia gramatical.
\end{abstract}

Palabras clave: responsabilidad penal; vínculo familiar; excusa absolutoria; delito patrimonial; enjuiciamiento; víctima.

\begin{abstract}
In Spanish criminal law, it is well known that there is an acquittal for patrimonial crimes, when the perpetrators or participants of such behavior have a familial nexus with the victims. The above mentioned acquittal becomes a general clause of exemption of criminal liability as per the jurisprudence (not as per the law), according to the established in the Law of criminal prosecution. However, the existence of that singular exception of liability in criminal patrimonial matters allows us to interpret that the general excuse established in the procedural law is totally devoid of legal validity, given the enormous contradiction between them, despite their grammatical coincidence.
\end{abstract}

Keywords: criminal liability, familial nexus, acquittal, patrimonial crime, prosecution, victim

Sumario. I. Consideraciones generales. II. La excusa absolutoria en los delitos patrimoniales. III. La RESPONSABILIDAD PENAL ENTRE PARIENTES DESDE PERSPECTIVAS JURISPRUDENCIALES. IV. DERROTEROS JURISPRUDENCIALES

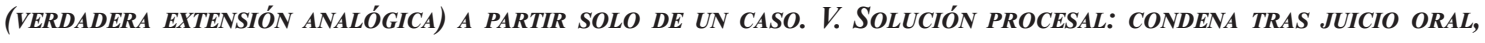

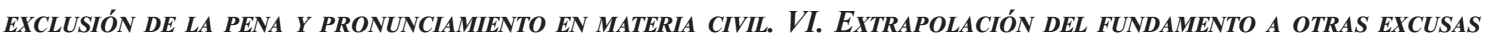
aBSOLUTORIAS CONTENIDAS EN EL CÓDIGO PENAL. VII. BIBLIOGRAFÍA. VIII. JURISPRUDENCIA

1 Profesor de Derecho Penal y Criminología. Universidad de Murcia. 


\section{CONSIDERACIONES GENERALES}

El derecho a reclamar justicia penal es el objetivo central de la acusación en un sistema judicial contradictorio. Además de esto, en el proceso penal se ventila, y se permite, que, junto a la petición de la imposición de una pena, se demande el resarcimiento del daño o perjuicio causado, siendo ésta última la misión singular de quien se encuentra en la posición de acusación particular, es decir, la víctima o perjudicado.

Sin embargo, el ejercicio de la acción penal, y con ello el derecho a solicitar de los Tribunales una resolución fundada (que esta sea favorable no entra dentro de tal derecho $^{2}$ ), y a iniciar un procedimiento penal contra un sujeto, no tiene la misma intensidad en todos los casos; bien al contrario, tal facultad se halla graduada en el Código Penal. Así, nos podemos encontrar con delitos que serán siempre perseguibles de oficio, aún sin la intervención del perjudicado (son aquellos delitos considerados, en su terminología tradicional, públicos) y otros casos en los que se establecen condiciones objetivas de perseguibilidad. Dentro de esta categoría tenemos, de un lado, aquellos en los que la acción penal (la denuncia o querella) debe ser presentada por la víctima (sobre todo en aquellos delitos en los que el consentimiento aparece como elemento de la tipicidad), quedando legitimado el Ministerio Fiscal solo a partir de la denuncia de la víctima (son los denominados, tradicionalmente, delitos semipúblicos), y, de otro, aquellos en los que no existe -en ningún caso- acusación pública y solo habrá proceso penal si existe querella de la víctima (son los llamados delitos privados, y que quedan limitados en España a los delitos de injurias y calumnias).

El ejercicio de la acción penal por parte de la víctima es, en definitiva, la consecuencia directa de su derecho fundamental a la tutela judicial efectiva.

\section{LA RESPONSABILIDAD PENAL Y LA FAMILIA}

Ahora bien, si lo que acabamos de exponer es el esquema ordinario del ejercicio de la acción penal por parte de las víctimas, existen dos excepciones importantes a esta facultad. De un lado, y según su redacción definitiva tras la LO 1/2015, la prevista en el artículo $268^{3}$ del Código Penal y, de otro, la establecida en el artículo $103^{4}$ de la Ley de Enjuiciamiento Criminal.

2 Así lo tiene afirmado de manera reiterada el Tribunal Constitucional. En efecto, es criterio constante del Tribunal Constitucional que "Los derechos y garantías previstos en el artículo $24 \mathrm{CE}$ no garantizan, ciertamente, la justicia de la decisión o la corrección jurídica de la actuación o interpretación llevada a cabo por los órganos judiciales comunes, pues no existe un derecho al acierto (entre muchas, SSTC 151/2001, de 2 Jul., FJ 5; y 162/2001, de 5 Jul., FJ 4). Y tampoco aseguran la satisfacción de la pretensión de ninguna de las partes del proceso (por todas, SSTC 107/1994, de 11 Abr., FJ 2; y 139/2000, de 29 May., FJ 4). Ahora bien, lo que en todo caso sí garantiza el expresado precepto es el derecho a que las pretensiones se desenvuelvan y conozcan en el proceso establecido al efecto, con observancia de las garantías constitucionales que permitan el derecho de defensa, y a que finalice con una resolución fundada en Derecho, la cual podrá ser favorable o adversa a las pretensiones ejercitadas (por todas, SSTC 50/1982, 173/2002).

3 "Están exentos de responsabilidad criminal y sujetos únicamente a la civil los cónyuges que no estuvieren separados legalmente o de hecho o en proceso judicial de separación, divorcio o nulidad de su matrimonio y los ascendientes, descendientes y hermanos por naturaleza o por adopción, así como los afines en primer grado si viviesen juntos, por los delitos patrimoniales que se causaren entre sí, siempre que no concurra violencia o intimidación, o abuso de la vulnerabilidad de la víctima, ya sea por razón de edad, o por tratarse de una persona con discapacidad".

4 "Tampoco podrán ejercitar acciones penales entre sí: $1^{\circ}$ Los cónyuges, a no ser por delito o falta cometidos por el uno contra la persona del otro o la de sus hijos, y por el delito de bigamia. $2^{\circ}$ Los ascendientes, descendientes y 
En cuanto a la primera de ellas, se trata de una exclusión de la pena en el ámbito familiar (elemento subjetivo de la exclusión) que va referida exclusivamente, por expreso imperativo del legislador, a los delitos patrimoniales (elemento objetivo de la exclusión ${ }^{5}$ ). Y ello, aunque, como ahora veremos, la inadecuada interpretación analógica de algunos tribunales haya terminado por entender aplicable (con carácter universal) dicha excusa absolutoria a cualquier acción que persiga, directa o indirectamente, cuestiones económicas entre parientes; Esto es lo que viene ocurriendo, por ejemplo, en los delitos societarios dentro de un contexto empresarial familiar.

Aun cuando se considera, de manera mayoritaria, que tal excusa absolutoria es una exclusión de la pena, otros autores entienden que la ausencia de necesidad de la pena se vincula a la relación parental del autor o partícipe con la víctima del delito, por lo que parece que realmente se está en presencia de una causa de exclusión personal ${ }^{6}$ de la pena; interpretación que, según estos autores, queda reforzada cuando en el artículo 268.2 del Código Penal se establece que la exención no alcanza a los que, participando en el delito, no se encuentran vinculados por la relación parental. ${ }^{7}$. De ahí que se haya afirmado, con toda la razón, que pese a su apariencia, esta última excepción -constante en todas las redacciones del precepto- cumple una función restrictiva, como ocurre en el Código Penal francés, y que vendría a justificar la propia existencia del párrafo que, de otro modo, sería innecesario (CASABÓ RUIZ ${ }^{8}$ ).

El fundamento clásico ${ }^{9}$ de la excusa absolutoria entre parientes -en materia patrimonial penal- se encuentra en que los bienes objeto del delito resultan de copropiedad

hermanos por naturaleza, por la adopción o por afinidad, a no ser por delito o falta cometidos por los unos contra las personas de los otros.

5 Así se acepta por la SAP Cuenca 113/2001, de 20 de diciembre (LA LEY 230130/2001) cuando afirma que el ámbito de aplicación de esta excusa absolutoria es limitado por razones objetivas y subjetivas.

6 De esta previsión han quedado fuera los partícipes del delito que no formaran parte del repetido grupo (MESTRE DELGADO, E, Delitos contra el patrimonio y contra el orden socioeconómico. La parte especial del Derecho Penal (Coord. LAMARCA PÉREZ, C). Madrid. 2016. P. 329

7 No puede olvidarse, como recuerdan ORTS BERENGUER/ GONZÁLEZ CUSSAC, que las excusas absolutorias, en general, constituyen supuestos de delito punible no penado, en los que el legislador ha considerado conveniente no castigar el delito en el caso concreto, pese a que en abstracto existía un hecho relevante, ilícito y reprochable. Se trata por lo general de causas vinculadas a la persona del autor, que no trascienden a los demás participantes en el delito (ORTS BERENGUER/ GONZÁLEZ CUSSAC, en Causas específicas de exclusión de la pena. Compendio de Derecho Penal. Parte General. Valencia. 2014. P 409.

8 CASABÓ RUIZ, JR. El parentesco adoptivo en el Código Penal español. Anuario de Derecho Penal y Ciencias Penales, Madrid, 1972. P. 120

9 Debe destacarse, como fundamento clásico, y por su evidente curiosidad, el análisis realizado por NAVARRETE URIETA, cuando afirmaba que "los comentaristas Tomás María de Vizmanos y Cirilo Álvarez Martínez abundan poco más o menos en las mismas razones que pusieron de manifiesto en la discusión parlamentaria del Código de 1922. Para estos autores "hay una ley más antigua que las sociedades y superior a sus leyes, la ley de la naturaleza; y seria inmoral que una ley humana exigiese de un padre, de un hijo, de una mujer, que sofocase esos honrosos sentimientos que ennoblecen tan bellos nombres y que enaltecen tanto a nuestra especie". Estos autores justifican la existencia de la exención en los sentimientos naturales que en este caso van acordes con la moral. Pero tales sentimientos no son patrimonio exclusivo de personas unidas por vínculos familiares, sino que pueden darse, y de hecho se dan, entre personas que no están vinculadas por tales lazos. Ahora bien, la admisión de una eximente basada en la existencia de tales sentimientos fuera del círculo familiar (como seria si, por ejemplo, la amistad o la gratitud), llevaría consigo grandes dificultades prácticas, ya que su prueba -según el parecer de los citados comentaristas- sería sumamente difícil. Por eso la ley abandona esta circunstancia subjetiva y sigue un camino objetivo eximiendo de la pena siempre que exista el parentesco exigido con independencia de la existencia o no del elemento afectivo. El admitir los conceptos de amigo y bienhechor, si bien satisfacen anhelos de justicia, por la imprecisión y vaguedad de los términos podría conducir a aplicaciones prácticas incorrectas". NAVARRETE 
familiar ("confusión de patrimonios"), dándose una disminución de la culpabilidad, bien porque esta copropiedad impide conocer quién es el verdadero propietario individual de la cosa (ÁLVAREZ VIZCAYA ${ }^{10}$ ), bien en el sentido de que el sujeto activo se sabe perdonado, faltando una exacta representación de la gravedad de la conducta (BAJO FERNÁNDEZ ${ }^{11}$ ). Sin embargo, y como también se ha dicho, el argumento defensivo de la excusa lo es al mismo tiempo ofensivo, pues obsérvese que, tras esta consideraci6n realmente poco exacta, se agita una idea significativa para estimar el parentesco como circunstancia atenuante: el agente puede sustraer una cosa, vgr, a su hermano, del que vive separado, en la creencia de que el mismo tolerará posteriormente el hurto realizado, en atención a la necesidad del primero; pero por otro lado, téngase en cuenta que la comisión de un delito contra la propiedad entre personas unidas por el vínculo de familia, puede traslucir un abuso de la confianza resultante de dicho vinculo; en un tal caso el parentesco no puede ser considerado como un hecho cuya concurrencia origina una menor gravedad de la conducta delictiva ${ }^{12}$ (CÓRDOBA RODA ${ }^{13}$ )

En la actualidad, el fundamento jurídico radicaría en la salvaguarda de la paz familiar ${ }^{14}$ excluyendo del mismo ciertas conductas a priori delictivas, siempre que se produzcan entre personas con estrechos vínculos familiares ${ }^{15}$ (Auto de la Audiencia Provincial de Almería de 24 de septiembre de 2015). En palabras de la Sala Segunda del Tribunal Supremo (STS 334/2003 ${ }^{16}$, de 5 de marzo), la razón de ser de la excusa absolutoria de los delitos contra la propiedad que no impliquen violencia ni intimidación entre los parientes incluidos en la excusa absolutoria del art. 268 del vigente $\mathrm{CP}$, se encuentra en una razón de política criminal que exige no criminalizar actos afectados en el seno de grupos familiares unidos por fuertes lazos de sangre en los términos descritos en el artículo 268 porque ello, provocar una irrupción del sistema per se dentro del grupo familiar que perjudicaría la posible reconciliación familiar, estaría en contra de la filosofía que debe inspirar la actuación penal de mínima intervención y última ratio, siendo preferible desviar el tema a la jurisdicción civil que supone una intervención menos traumática y más proporcionada a la exclusiva afectación de intereses económicos como los únicos cuestionados,

URIETA, JM. El encubrimiento entre parientes (artículo 18 del Código Penal). Anuario de derecho penal y ciencias penales, Tomo 13, Fasc/Mes 2, 1960. PP. 233-234

10 ÁLVAREZ VIZCAYA, M. La excusa absolutoria de los delitos patrimoniales: artículo 268 del CP, en Estudios jurídicos en memoria de José María Lidón. Bilbao. 2002. P. 28

11 BAJO FERNÁNDEZ, M, El parentesco en Derecho Penal. Barcelona. 1973. P 102.

12 En igual sentido, STS de 25 de abril de 1963.

13 CÓRDOBA RODA, J. El parentesco como circunstancia mixta de modificación de la responsabilidad penal. Anuario de derecho penal y ciencias penales, Tomo 20, Fasc/Mes 1-2, 1967. PP. 182-183

14 En este mismo sentido se pronuncia LUZÓN CÁNOVAS al señalar que En este caso, el fundamento de la limitación se encuentra en el superior valor de la institución familiar, que no debe ser atacado por el ejercicio de acciones en las que ningún interés personal o directo existe (LUZÓN CÁNOVAS, A. La acción popular. Análisis comparativo con la acusación particular. Diario La Ley, N. . 5483, Año XXIII, 15 de Febrero de 2002, Ref. D-51, pág.. 1796, tomo 2, Editorial LA LEY. P. 11).

15 Como señala NAVARRO FRÍAS, recordando a SILVA SÁNCHEZ, la excusa absolutoria prevista en el artículo 268 tiene una finalidad vinculada al principio de subsidiariedad, en tanto que se entiende que la familiar es una instancia de control social informal que posee instrumentos reguladores que puede mostrarse como suficientes en el caso concreto (NAVARRO FRÍAS, en ROMEO CASABONA/ NAVARRO FRÍAS, en Delitos contra el patrimonio y el orden socioeconómico. II. Defraudaciones, insolvencias punibles, alteración de precios en concursos y subastas públicas y daños, Derecho penal. Parte especial. Granada. 2016. P. 394); SILVA SÁNCHEZ, J. Hermanos, pero no primos. Los delitos patrimoniales y el alcance de la excusa absolutoria del artículo 268 del Código Penal. Una crítica a la doctrina del Tribunal Supremo, Diario La Ley, Sección Doctrina, 2001, Ref. D-126, Tomo 4. 2001. P 1549).

16 LA LEY 1869/2003 
de ahí que se excluya los apoderamientos violentos o intimidatorios en los que quedan afectados valores superiores a los meramente económicos como son la vida, integridad física o psíquica, la libertad y seguridad.

Entiendo que esta fundamentación doctrinal es una mera reinterpretación descontextualizada, basada en un derecho penal de mínimos al que no pertenece el artículo 268 del Código Penal. El citado precepto, en sus distintas versiones, existía en el Código Penal de 1822 (artículo $756^{17}$ ), en el Código Penal de $1848^{18}$ (ubicado en el entonces articulo 479), Código Penal de 1928 (artículo 759), Código Penal de 1932 (artículo 557), Código Penal de 1944 (artículo 564, mantenido después en el texto refundido de 1973), llegando hasta el actual Código Penal de 1995 en su artículo 268; por tanto es una norma de arraigo histórico en España. Es decir, su génesis se encuentra en una era legislativa que, precisamente, no podía considerarse de mínimos, por lo que cualquier interpretación modernista del precepto, basada en principios como el de intervención mínima y que olvida su asentamiento doctrinal tradicional y estricto, puede entrañar, y lo consigue, una creación ex novo de lo que, sin duda alguna, no es nuevo para el Derecho penal español.

Adviértase que Sentencias del Tribunal Supremo que bien pudieran calificarse de históricas ya afirmaban, respecto del particular, que nos encontramos ante un precepto que debía interpretarse restrictivamente, sin que pudiera extenderse a otros delitos ni a otras personas distintos de los expresados en la norma (así lo afirmaban las SSTS de fecha 18/11/1878, 16/3/1909, 28/9/1927, 6/4/1954, 25/1/1955, 22/5/1956, 14/5/1963, 27/1/1967, 24/2/1968, 15/3/1969, 10/11/1969, 23/1/1970, 2/5/1972 ${ }^{19}, 10 / 06 / 1972,21 / 2 / 1975,26 / 2 / 1975^{20}$ ). Es decir, que, si en un derecho penal de máximos, la jurisprudencia aconsejaba no caer en interpretaciones extensivas, pretender ahora una aplicación extensiva, en la era del derecho penal de mínimos, resulta una tarea algo contradictoria, sobre todo cuando para tal menester se realiza un claro forzamiento del principio de legalidad y se entra en la siempre criticable creación judicial del Derecho penal. Matices, todos ellos, hábilmente vislumbrados y analizados por COBO DEL ROSAL ${ }^{21}$ en el año 1976.

En cualquier caso, y al margen de las críticas que pueden afirmarse respecto de la protección abstracta a la familia ${ }^{22}$, lo que el artículo 268 del Código Penal excluye, desde perspectivas de política criminal, es la posibilidad de sancionar penalmente a los parientes aun cuando el hecho cometido sea típicamente antijurídico y culpable, de ahí que esta

17 ART. 756. "El marido que quita o toma las cosas de su mujer, la mujer que toma ó quita las de su marido, el viudo o viuda que toma o quita las que hubiesen pertenecido á su difunto cónyuge, el padre o madre que quita o toma las de sus hijos o descendientes; los hijos y descendientes que toman o quitan las de sus padres o madres, $\mathrm{u}$ otros ascendientes, y todos aquellos que se hallen en el mismo grado de afinidad, no pueden ser demandados sino para la restitución y resarcimiento. Pero todos aquellos que hubieren participado á sabiendas de la cosa tomada, o que lo hubiesen ocultado o hubieren auxiliado, serán castigados como reos o de hurto, o como encubridores o auxiliadores respectivamente".

18 De donde nace la formulación actual de la excusa absolutoria, al margen de las modificaciones concretas que han ido incorporándose en los códigos penales y sus respectivas reformas. Así lo recordaba NAVARRETE URIETA, JM. El encubrimiento entre parientes... Op. Cit. P. 233.

19 STS 2901/1972

20 Roj: STS 1135/1975

21 COBO DEL ROSAL, M. Código Penal con jurisprudencia y concordancias. Civitas. Madrid. 1976. P. 465

22 Como afirmó COBO DEL ROSAL, no debe olvidarse que la familia está compuesta por miembros individuales que tampoco pueden ser condenados a los abismos de la indefensión, al socaire de la abstracción de la familia (COBO DEL ROSAL, M. Sobre el ejercicio de acciones penales entre parientes en los delitos contra el patrimonio y el orden socioeconómico. Cuadernos de política criminal. Madrid 2002. P.557 
exclusión de pena no alcance a los terceros que participen en la conducta. Respecto de la relación parental en el derecho penal nos encontramos también con el artículo 103 Ley de Enjuiciamiento Criminal; Precepto de larga tradición en el Derecho español y cuyo tenor literal, incluso su vigencia, debe ser valorado a la luz de las reformas del Código Penal. Y ello a pesar de que en la exposición de motivos de la Ley Orgánica 14/1999, de 9 de junio, de modificación del Código Penal de 1995, en materia de protección a las víctimas de malos tratos y de la Ley de Enjuiciamiento Criminal, se afirmara que la redacción del artículo 103 se revisó con el objeto de ponerla en consonancia con el vigente Código Penal.

Se trata de una norma, ubicada en un cuerpo normativo procesal, y cuya trascendencia sustantiva material colisiona de manera irreparable -en términos hermenéuticoscon las disposiciones del Código Penal. De tal forma que si bien podemos admitir un Código Penal que limita el proceso por cuestiones sustantivas (el proceso no es más que un vehículo para la aplicación del derecho material), no parece plausible un código procesal que entra en valoraciones sustantivas, máxime cuando éstas resultan contradictorias con el Código Penal (norma especial, posterior y jerárquicamente superior, como sabemos).

$\mathrm{La}$, a nuestro juicio inadecuada, tendencia jurisprudencial expansiva que se produce sobre este particular, esto es, la tajante declaración de ausencia de responsabilidad penal entre parientes, nos obliga a justificar y recordar por qué la excusa absolutoria no resulta aplicable a cualquier delito (entiéndase a cualquier delito que se encuentre fuera de los de naturaleza patrimonial).

Para ello, y desde perspectivas de estricta legalidad, se ha de empezar indicando que el artículo 268 del Código Penal se encuentra en el capítulo X denominado "disposiciones comunes a los capítulos anteriores", dentro del Titulo XIII ("de los delitos contra el patrimonio y contra el orden socioeconómico"), es decir, que el artículo 268 Código Penal solo es de aplicación a los capítulos 1 al 9 del Titulo XIII; Dicho de otra manera, solo afecta a los delitos patrimoniales -strictu sensu- con expresa exclusión de aquellos otros que protegen el orden socioeconómico, y que se ubican a partir del artículo 270 (capítulo XI) ${ }^{23}$.

De ahí que se haya afirmado que si aceptamos la sistemática formal sustentada por el legislador de 1995, hemos de reconocer que de los XIV capítulos que componen este Título XIII, la línea divisoria entre delitos patrimoniales y delitos socioeconómicos la marca el Capitulo X, puesto que contiene no solo una referencia genérica a las "disposiciones comunes a los capítulos anteriores", sino sobre todo, porque el artículo 268, incluido en el mismo, al contemplar una excusa absolutoria tradicional en nuestra legislación, ha marcado claramente la diferencia entre delitos patrimoniales y los que no lo son (PERIS RIERA ${ }^{24}$ ).

23 En idéntico sentido, DOMINGO MONFORTE cuando afirma que el art. 268 del Código Penal permite la exclusión de la responsabilidad criminal para el autor de un delito de carácter patrimonial (aquellos incluidos dentro del Título XII del Código Penal, denominado «Delitos contra el patrimonio y contra el orden socioeconómico») que ostente una determinada relación de parentesco con las víctimas del mismo, siempre y cuando la infracción se haya llevado a cabo sin violencia ni intimidación (DOMINGO MONFORTE, J. La Administración desleal y la excusa absolutoria de parentesco. Diario La Ley, No 9158, Sección Tribuna, 14 de marzo de 2018, Editorial Wolters Kluwer. P. 1)

24 PERIS RIERA, J, Derecho penal económico y Código Penal español de 1995: Aproximación a la sistemática de los delitos contra la economía. en Revista de Derecho penal y Procesal penal, $N^{\circ} 3 / 2006$. Buenos Aires. 2006. P. 427 
Por esta razón, GONZÁLEZ RUS ${ }^{25}$ afirma que, en realidad, ni el propio Código cree que la diferenciación (entre los delitos patrimoniales y los delitos contra el orden socioeconómicos) sea innecesaria, pues sistemáticamente la línea fronteriza entre unos y otros delitos la sitúa en las disposiciones comunes del Capítulo X, en cuyo artículo 268 parece calificar de "delitos patrimoniales" a los recogidos en los capítulos anteriores (I al IX). En definitiva, hay base para decir que todos los delitos que se encuentran tipificados en los capítulos I al IX del Título XIII del Libro Segundo del Código Penal son delitos contra el patrimonio, mientras que los delitos tipificados en el Capítulo XII a XIV del mismo Título serían delitos contra el orden socio-económico (BENÍTEZ ORTÚZZAR ${ }^{26}$ )

No se puede ignorar, por tanto, la importancia sistemática que la doctrina penal ha otorgado unánimemente al precepto que ocupa el Capítulo X de este Título y cuyo rótulo es precisamente el de "Disposiciones comunes a los Capítulos anteriores", impidiendo, expressis verbis, su proyección sobre los Capítulos siguientes. Y si esta imposible aplicación de la excusa absolutoria ha de predicarse de los delitos contra el orden socio-económico, con mayor motivo resulta indiscutible su imposible aplicación a otros delitos fuera del Título XIII (por muy conexos que éstos resulten).

Sin embargo, en la práctica forense es frecuente encontrar casos en los que, de manera contraria a esta interpretación sistemática, se dilucida algo que obviamente no quiso el legislador. Nos referimos a la aplicación universal de la excusa absolutoria entre parientes. Y decimos que no es respetuoso con el principio de legalidad penal, porque de haber querido el legislador tal generalidad, simplemente hubiera ubicado el precepto en el último Capítulo del Titulo XIII, o más directamente en los principios generales del Libro I del Código Penal. Y no es de recibo que la jurisprudencia se irrogue tareas de legislador. Algo que últimamente está ocurriendo de forma más que excepcional.

\section{LA RESPONSABILIDAD PENAL ENTRE PARIENTES DESDE PERSPECTIVAS JURISPRUDENCIALES.}

Esta interpretación jurisprudencial extensiva excluye, de manera absoluta, la responsabilidad penal entre parientes (salvo que concurra violencia o intimidación o vulnerabilidad de la víctima ${ }^{27}$ ) atendiendo al artículo 268 del Código Penal y, en cuanto exceda de su aplicación $^{28}$, en base al artículo 103 de la Ley de Enjuiciamiento Criminal.

Según este criterio, nuestra legislación establece una doble limitación legal respecto de la incidencia del Derecho Penal en el seno de la familia, con la finalidad de evitar el enfrentamiento familiar. Esta doble limitación vendría regulada, de un lado, en la norma procesal penal y, de otro, en el derecho penal sustantivo.

En el primer caso, estaríamos ante el veto del ejercicio de la acción penal para determinadas personas en función de la relación de parentesco que guarden con los pre-

25 GONZÁLEZ RUS, JJ, en Delitos contra el Patrimonio y contra el orden socioeconómico (I), en Sistema de Derecho Penal Español. Parte Especial (Coord. Morillas Cueva). Madrid. 2011. P 409.

26 BENÍTEZ ORTÚZAR, IF, en Delitos contra el Patrimonio y contra el orden socioeconómico (I), en Sistema de Derecho Penal Español. Parte Especial (Dir. Morillas Cueva). Madrid. 2016. P 396.

27 Esto último solo a partir de la reforma del 2015 del Código Penal.

28 Aun cuando este ámbito de aplicación observamos que, lamentablemente, se extiende o reduce a criterio del intérprete judicial. 
suntos infractores (artículo 103 Ley de Enjuiciamiento Criminal); Y en el segundo, de carácter sustantivo, se eximiría de responsabilidad penal en aquellos delitos patrimoniales (o de contenido último económico) en los que hubieran podido incurrir determinadas personas contra otras con las que existe una relación típica de parentesco (artículo 268 del Código Penal).

La jurisprudencia entiende correcta una interpretación analógica in bonam partem ${ }^{29}$ de esta excusa absolutoria, permitiendo así extender el alcance beneficioso del artículo 268 a los delitos societarios (así lo expresa la STS 42/2006, de 27 de enero de 2006, LA LEY 10927/2006 ) y delitos conexos de contenido último económico. En este mismo sentido se expresa algún autor, cuando afirma que la interpretación legal es distinta en cuanto se beneficia al acusado que en aquello que lo perjudica, conforme al aforismo odiosa sunt restringenda, favorabilia sunt amplianda, que tiene plasmación en nuestro ordenamiento jurídico punitivo tanto en la prohibición de analogía en malam partem,..,lo que conduce a la interpretación extensiva y favorable de aquellos elementos beneficiosos para el acusado (RODRÍGUEZ RAMOS ${ }^{30}$ )

Así las cosas, si el entorno de los delitos societarios sigue siendo la familia (empresas familiares) procede, según la jurisprudencia, eximir de responsabilidad penal entre parientes, en base a la excusa absolutoria del artículo 268 del Código Penal, en aquellos supuestos en los que, bajo la cobertura o amparo de la figura societaria, intentan dilucidar las responsabilidades individuales de quienes la componen (STS 42/2006 31 , de 27 de enero).

Véase en este sentido la SAP Burgos 360/2013 ${ }^{32}$, de 3 de septiembre cuando no tiene empacho en señalar que nuestra legislación establece una doble limitación legal respecto de la incidencia del Derecho Penal en el seno de la familia, proyectada a evitar un enfrentamiento de unos familiares contra otros para mejor salvaguardar la paz en el seno de las relaciones parentales más próximas: una, a través del proceso penal y, otra, del derecho penal sustantivo, vetando, en el primer caso, el ejercicio de la acción penal a determinadas personas en función de la relación de parentesco que guarden con los presuntos infractores (artículo 103 de la Ley de Enjuiciamiento Criminal) y otra, declarando la exención de la responsabilidad penal en que hubieran podido incurrir determinadas personas por la comisión de delitos de carácter patrimonial contra otras personas en función de la relación de parentesco existente entre ellas (artículo 268 del Código Penal).

Nos parece inasumible, en términos jurídico penales, que se indique que existe una doble limitación a la responsabilidad penal entre parientes (procesal y penal) dado que sin proceso - estamos ante el ejercicio de la potestad punitiva del Estado- no hay derecho penal. Dicho de otro modo, si se entiende que procesalmente no se puede ejercitar acción penal entre parientes resulta inútil referir las limitaciones que establece el Código Penal,

29 Fundamento Décimo, apartado 7 STS 42/2006, de 27 de enero (LA LEY 10927/2006) : "Si tal teoría se ha utilizado en contra del reo para impedir que bajo la cobertura societaria se cometan impunemente delitos patrimoniales, con más razón, siguiendo una interpretación "in bonam partem" debemos levantar el velo y concluir que los intereses de la sociedad son los mismos y además coincidentes con los de los socios, todos ellos hermanos de la querellante y por tanto incluidos en el alcance beneficioso u órbita de aplicación de la excusa absolutoria prevista en el art. 268 C.P”.

30 RODRÍGUEZ RAMOS, L. Código Penal concordado con jurisprudencia sistematizada y leyes penales especiales y complementarias. La Ley. Madrid. 2007. PP. 668-669

31 LA LEY 10927/2006

32 LA LEY 136450/2013 
y ello salvo que se indique que existe la posibilidad -que desconocemos- de aplicar el Código Penal sin el proceso penal.

Por ello, no podemos estar más en desacuerdo con esa interpretación extensiva analógica. Es más, desde el punto de vista práctico, no habría solución alternativa a esta limitación que se infiere a la víctima, pues cuando no resulta de aplicación el artículo 268 del Código Penal se pretende aplicar el criterio general del artículo 103 de la Ley de Enjuiciamiento Criminal ${ }^{33}$; El mismo razonamiento, en sí mismo, es falso en términos lógico jurídicos, y así lo demuestra su interpretación a sensu contrario: Si dándose el presupuesto procesal del artículo 103 Ley de Enjuiciamiento Criminal (relación de parentesco) se tiene que descartar cualquier posible aplicación de derecho penal sustantivo entre parientes, resulta irrelevante lo que, por su parte, se pueda establecer en el artículo 268 del Código Penal, pues sencillamente no hay mayor ámbito de aplicación de una Ley (Ley de Enjuiciamiento Criminal) que aquel que contempla -en este caso excluyéndolos- absolutamente todos los supuestos. En consecuencia, esta corriente jurisprudencial, siguiendo un criterio irrazonable, permite excluir de responsabilidad penal a las familias en todos los casos, salvo que concurra violencia, intimidación ${ }^{34}$, o vulnerabilidad. Lo que, como veremos, supone una efectiva e indebida despenalización "de facto" de delitos para los que nunca el legislador previó tal excusa absolutoria.

En sentido más crítico, aunque tampoco determinante, se pronuncia la STS $933 / 2010^{35}$, de 22 de octubre, al indicar que resulta indudable que los planos jurídicos sobre los que han de operar los artículos 268 del Código Penal y 103 de la Ley de Enjuiciamiento Criminal no se superponen. Así, mientras que el primero centra su objetivo en la regulación de las excusas absolutorias derivadas del parentesco, el segundo se refiere a los presupuestos del ejercicio de la acción penal.

Pero también es cierto que la exégesis del uno no puede hacerse con absoluta independencia del otro. No tendría sentido aceptar una interpretación literal del artículo 103 de la Ley de Enjuiciamiento Criminal que condujera a excluir la posibilidad de ejercer la acción penal por aquel que, [por ejemplo], habiendo iniciado un proceso de separación o divorcio, viera menoscabado su patrimonio por acciones de su cónyuge, sobre todo porque, desde el momento de la separación de hecho, ya no tendría a su favor la exención de responsabilidad que el artículo 268 del CP le otorgaba durante la convivencia.

Resultaría un contrasentido, según dice esta Sentencia, que la persecución de hechos delictivos no amparados en ninguna excusa por razón del parentesco, fuera sometida por el legislador a limitaciones que no guardan relación con el fundamento mismo de la exención. Si el ataque al patrimonio de uno de los cónyuges ya no puede resultar impune por desbordar los límites del artículo 268 del Código Penal -separación de hecho o demanda de separación, nulidad o divorcio-, carecería de lógica que, con el cuestionable fundamento de la fidelidad a una interpretación estrictamente literal del artículo 103 de la

33 Coincidimos, con SERRANO GÓMEZ, cuando dice que la mejor solución, para los fines que persigue el legislador, sería transformar estos casos en delitos perseguibles a instancia de parte, dejando en manos del perjudicado la apreciación de si es oportuno hacer uso de las acciones penales y perdonar, o incluso recurrir a la vía civil (SERRANO GÓMEZ, A, Derecho Penal. Parte Especial, Madrid, 2000, p. 437).

34 Bien sea entendido como delitos contra las personas (artículo 103 Ley de Enjuiciamiento Criminal), bien como violencia o intimidación (artículo $268 \mathrm{CP}$ )

35 LA LEY 203317/2010 
Ley de Enjuiciamiento Criminal, la víctima no pudiera promover el ejercicio de la acción penal con el fin de reparar la ofensa sufrida por el delito.

En definitiva, cualquier delito cometido entre cónyuges, en ausencia de los presupuestos que justifican la aplicación de la excusa absolutoria prevista en el artículo 268 del Código Penal, podrá ser perseguido por la víctima, sin limitaciones derivadas de la literalidad del artículo 103 de la Ley de Enjuiciamiento Criminal, cuyo contenido ha de ser interpretado en estrecha relación con el fundamento y los presupuestos de la exención.

Con todo, la génesis del problema se encuentra en la existencia de un procedimiento penal obsoleto que deja casi sin protección penal a unas personas frente a la comisión de graves hechos delictivos, por el simple hecho de que les una con el autor del delito una relación de consanguinidad o afinidad que poco o nada tiene que ver con la convivencia o relaciones verdaderamente afectivas (ÁLVAREZ VIZCAYA ${ }^{36}$ ).

Entendemos, por ello, que la interpretación jurisprudencial que solapa de manera rotunda el ámbito aplicativo del artículo 268 Código Penal con el del artículo 103 Ley de Enjuiciamiento Criminal es contraria al principio de legalidad. De un lado, porque desde perspectivas de legalidad penal no tendría sentido decir que el legislador ha incluido una excusa absolutoria específica en los delitos patrimoniales cuando supuestamente, y al mismo tiempo, ha excluido, a través del artículo 103 de la Ley de Enjuiciamiento Criminal, la responsabilidad penal en todos los delitos. Y de otro, consecuencia de lo anterior, porque si se establece de manera específica dicha exclusión en el artículo 268 del Código Penal, debe considerarse, por criterio de especialidad (la responsabilidad penal la establece o excluye el Código Penal), jerarquía (el Código Penal es ley orgánica y la Ley de Enjuiciamiento Criminal ley ordinaria) o temporal (el Código Penal es ley posterior a la Ley de Enjuiciamiento Criminal) que el artículo 103 de la Ley de Enjuiciamiento Criminal se encuentra derogado en aquellos casos que contradiga al Código Penal. Existe pues un conflicto de leyes que debe ser resuelto -a favor del Código Penal- a fin de evitar interpretaciones contra legem que desvirtúen la unidad y coherencia del ordenamiento jurídico.

La Ley de Enjuiciamiento Criminal no puede nunca contradecir, en términos sustantivos (y la pena lo es) aquello que, de manera específica, establece el Código Penal. Entender lo contrario, esto es, considerar que la ley adjetiva puede eximir de responsabilidad penal aun cuando el Código Penal nada diga al respecto, o diga justo lo contrario, no solo supone una vulneración patente del principio de legalidad sino una abierta conculcación del derecho a la tutela judicial efectiva de la víctima.

Incluso aunque consideráramos que el citado artículo 103 Ley de Enjuiciamiento Criminal habla de proceso, y no de derecho penal, la realidad es que esta corriente jurisprudencial lo interpreta en términos sustantivos y no procesales, otorgando con ello, y de manera inasumible, un privilegio de impunidad a quien es culpable por una conducta con relevancia penal. Máxime cuando la excusa absolutoria, como es pacífico en la doctrina y la jurisprudencia, supone solo una limitación -exclusión- de la pena y no un juicio negativo de la antijuridicidad o de la culpabilidad.

Por ello, la aplicación de la excusa absolutoria, y la consiguiente sentencia absolutoria, no impide que ésta realice un pronunciamiento sobre la responsabilidad civil

36 ÁlVAREZ VIZCAYA, M., La excusa absolutoria de.... Op. Cit. P. 39. 
(STS 361/200737, de 24 de abril). En este mismo sentido se pronuncia la SAP de Cuenca $113 / 2001^{38}$, de 20 de diciembre, al afirmar que, no obstante, es llano que el artículo 268 del Código Penal excluye la responsabilidad criminal pero no la civil, de tal suerte que conforme a lo establecido en los artículos 109 y siguientes del texto punitivo corresponde pronunciarse respecto a esta cuestión.

Y esto en el hipotético caso de que, tras el plenario, se entendiera de aplicación la excusa absolutoria en términos extensivos (para delitos no patrimoniales en sentido estricto), situación que, jurídico-penalmente hablando, entendemos más que discutible en los casos que describimos.

Es más, para evitar la impunidad que se defiende por este sector jurisprudencial, el Código Penal llega a establecer condiciones objetivas de perseguibilidad en algunos delitos, dejando que sea la víctima quien decida si desea que el delito sea o no perseguido, sin más limitación que esa voluntad de iniciar el proceso. Por tanto, incluso una interpretación sistemática y global del Código Penal impediría la interpretación limitadora que, del artículo 103 Ley de Enjuiciamiento Criminal, se viene realizando por algún sector jurisprudencial. Más aún, si el legislador hubiera diseñado un derecho penal al estilo del creado por este sector jurisprudencial, habría contemplado la posibilidad de establecer, para el resto de delitos, el perdón del ofendido como último recurso para dejar los conflictos familiares extramuros del Derecho Penal. En lugar de ello, solo se establece esta excusa en los delitos patrimoniales a título de perdón legal (SÁINZ CANTERO ${ }^{39}$ ), y no voluntario.

Esta criticable aplicación - a la carta- de preceptos y principios del Código Penal termina por someter los conflictos familiares con relevancia penal a reglas no legales y a interpretaciones de moda -discutibles incluso de lege ferenda-, causando absoluta indefensión e inseguridad jurídica.

Por ello mismo, lo que no tiene sentido es que en un afán, por lo demás desmesurado e irracional, de no involucrarse en las cuestiones de la familia se esté desprotegiendo a los individuos que la integran y con ello, en muchos casos, perjudicando a las propias familias que no saben qué hacer ni a quién recurrir, y mucho más en el caso de personas jurídicas -sociedades- en las que el perjuicio económico alcanzaría, desde luego, a empelados, gerentes, contratados, etc., que no tienen ninguna vinculación familiar con el representante del capital $\left(\mathrm{COBO}\right.$ DEL ROSAL $\left.{ }^{40}\right)$.

\section{DERROTEROS JURISPRUDENCIALES (VERDADERA EXTENSIÓN ANALÓGICA) A PARTIR SOLO DE UN CASO}

Esta jurisprudencia no inició tal andadura hermenéutica de manera abierta y tajante. En efecto, es suficiente con ver la Sentencia número $42 / 2006^{41}$ para observar que en ningún caso se prevé la posibilidad, en fase instructora, de un archivo directo de las actuaciones

37 LA LEY 17325/2007

38 LA LEY 230130/2001

39 Perdón legal que encuentra su fundamento en razones de político-criminales, de oportunidad política o de utilidad (SÁINZ CANTERO, en Lecciones de Derecho Penal. Parte General. Barcelona. 1990. P. 757.

40 COBO DEL ROSAL, M. Sobre el ejercicio de acciones penales entre parientes... Op. Cit. P.557

41 LA LEY 10927/2006 
sin necesidad de celebrar juicio oral. Es más, dicha resolución tan solo establecía un obiter dicta, planteado en términos de pura hipótesis, para el supuesto de hecho de aquella sentencia, y sin ningún ánimo de sentar un criterio determinante y vinculante para el resto de casos. Dicha hipótesis solo partía de considerar a la sociedad mercantil familiar como perjudicada y no a los socios querellantes. En tal supuesto, en realidad, se hablaba de que, tras aquel delito societario, se estaba denunciando un delito de apropiación indebida, hecho absolutamente distinto al que analizamos ya que la apropiación indebida sí es un delito patrimonial. Es más, la cuestión de si la administración desleal es o no un delito patrimonial lo ha despejado la última reforma del Código Penal (LO 1/2015) al extraer y reubicar tal delito dentro del delito patrimonial de la apropiación indebida. Sin embargo, con bastante anterioridad a dicha reforma, se estaba interpretando la naturaleza patrimonial de este delito societario sin que su ubicación sistemática autorizara en ningún caso esta interpretación.

Pero, es más, en la STS número $83 / 2010^{42}$, de 11 de febrero (usada, esta sí, para motivar el archivo de la causa desde el inicio del procedimiento) se puede comprobar cómo se acuerda en fase de juicio oral la absolución toda vez que el Ministerio Fiscal no ejercitó la acusación y la acusación particular solo lo hacía por delitos patrimoniales sensu strictu. En dicha Sentencia se indica por el ponente que el perjudicado puede denunciar a los solos efectos de que el Ministerio Fiscal asumiera el ejercicio de la acción pública y ejercer, eventualmente, la acción civil. Incluso se llega a manifestar que la interposición de una denuncia por el pariente/víctima, con incumplimiento de la prohibición general del artículo 103 Ley de Enjuiciamiento Criminal, supone incurrir en fraude de ley ${ }^{43}$, extremo este sobre el que más adelante haremos una mención especial.

Como signo evidente de que la tendencia jurisprudencial que analizamos no responde a un criterio uniforme y constante, debemos hacer referencia a la Sentencia del Tribunal Supremo número 933/2010 ${ }^{44}$, de 22 de octubre. Esta Resolución contradice abiertamente la interpretación analógica; señal inequívoca de que la cuestión no es sencilla ni permite cercenar el ejercicio de la acción particular, sin vulnerar con ello el principio a la tutela judicial efectiva de la víctima/pariente.

Se señala en la citada sentencia que, aunque el giro de una sociedad mercantil limitada se ajuste a un modelo familiar de funcionamiento, no puede conllevar a la derogación del régimen jurídico que define la actuación de las sociedades limitadas en el tráfico mercantil. El día a día de una determinada sociedad, incluso, el flexible acatamiento de las reglas legales impuestas con carácter general por el Real Decreto Legislativo 1/2010 (Texto refundido de las sociedades de capital), no puede conducir a la anulación, por vía de hecho, de las notas definitorias de ese tipo de persona jurídica. La sociedad limitada, una vez constituida, ha de ajustar el régimen jurídico de su funcionamiento al esquema normativo que el derecho mercantil exige, tanto en las relaciones frente a terceros, como en el ámbito intraorgánico que sería propio de la vida societaria. Mas aún, ese preten-

42 LA LEY 3126/2010

43 Fundamento de Derecho único STS 83/2010, de 11 de febrero (LA LEY 3126/2010): "La Audiencia ha sobreseído libremente la causa basada en la querella del recurrente contra sus cuñados por los delitos de los arts. 252 y 292 CP, basándose en el art. 103 Ley de Enjuiciamiento Criminal y sosteniendo que esta disposición contiene un (SIC) "cuya inobservancia podría suponer incurrir en fraude de ley" y considerando que "el texto legal es clarísimo y no hace distinciones".

44 LA LEY 203317/2010 
dido modelo societario familiar, con virtualidad derogatoria de las notas esenciales de cualquier sociedad limitada, no puede prolongar su cuestionable vigencia cuando las relaciones familiares han iniciado un proceso irreversible de deterioro, que se traduce en la interposición de acciones judiciales.

En esta misma Sentencia de la Sala Segunda del Tribunal Supremo STS 933/2010 se afirma que el artículo 103 Ley de Enjuiciamiento Criminal tampoco afecta a la capacidad de denunciar ${ }^{46}$, sino a la capacidad de mostrarse parte como acusación particular y, por tanto, para ejercer una pretensión acusatoria ${ }^{47}$. Extremo éste en el que también existen discrepancias jurisprudenciales ${ }^{48}$, pues en no pocos casos, como hemos visto más arriba, se está considerando que la mera denuncia es un fraude de ley, que merece incluso la imposición de costas al denunciante/pariente.

Véase, en tal sentido, el curioso razonamiento que realiza la SAP Zaragoza 18/2016 49 , de 25 de enero: "Nos encontramos ante el ejercicio de acciones penales por delitos patrimoniales y de falsedad de una persona contra su cuñado, lo que está prohibido por el artículo 103 de la Ley de Enjuiciamiento Criminal, lo cual se debió ya apreciar en fase de instrucción. Como dice la STS 834/200750, de 22 de octubre, que los órganos jurisdiccionales intervinientes en el proceso no hubieran declarado la falta de legitimación activa para el ejercicio de la acción penal contra el acusado por su hermana y el marido de ésta (hermano por afinidad), en momento anterior a la celebración del juicio oral, no empece en modo alguno la realidad de que el artículo 103 Ley de Enjuiciamiento Criminal no permite a ninguno de ellos tal ejercicio acusatorio cuando no se trata de delitos cometidos contra las personas. La nitidez de la norma, que no admite interpretaciones, tenía que ser necesariamente conocida por el Letrado de las acusaciones particulares, a pesar de lo cual persistieron en mantener la imputación en el tiempo, sin razón o justificación alguna en clara y patente rebeldía contra la disposición legal. Esta contumacia en la ilegalidad, [sigue indicando esta Sentencia], no puede tener otra causa que la mala fe procesal y la temeridad de quienes así obraron, por lo que, sin duda, procede la estimación de lo establecido en el artículo $240.3^{\circ}$ Ley de Enjuiciamiento Criminal, imponiendo a los querellantes particulares el pago de las costas correspondientes al indebidamente querellado".

45 LA LEY 203317/2010

46 Criterio compartido por DOMINGO MONFORTE cuando afirma que "el art. 103 de LECrim, no introduce una verdadera limitación al ejercicio de la capacidad para denunciar, sino al ejercicio de la acción penal a los allí vetados, o lo que es lo mismo, a la voluntad para constituirse en parte acusadora ejercitando una genuina pretensión, lo que no impide que el Ministerio Fiscal, teniendo noticia de los hechos y bajo su legitimación, accione y sostenga la acción penal, participando en el proceso el cónyuge, ascendiente, descendiente o hermano, en calidad de actor civil” (DOMINGO MONFORTE, J. La Administración desleal y la excusa absolutoria ... Op. Cit. P. 3)

47 En el mismo sentido, SAP Les Illes Balears 111/2017, de 22 de diciembre de 2017 (LA LEY 231992/2017)

48 Ejemplo de este criterio contrario lo encontramos en la SAP Valencia, 237/2017, de 7 de abril de 2017 (LA LEY 68044/2017), cuando afirma que "la limitación establecida en el art. 103 de la L. E. Crim no va referida a la capacidad de denunciar, sino al ejercicio de la acción penal o, lo que es lo mismo, a la capacidad para constituirse como parte acusadora formulando una pretensión penal. Así se desprende con claridad del epígrafe que rotula el Título IV del Libro I de la LECrim, referencia sistemática en la que se incluye el art. 103 y que alude a "Las personas a quienes corresponde el ejercicio de las acciones que nacen de los delitos y faltas ", por lo que hemos de concluir, como así hace la defensa, que Eugenia carece de acción penal por el delito de falsedad -también por los delitos societarios a que más adelante aludimos- contra su hermano Rogelio, lo que no quiere decir que no pueda formular acusación el Ministerio Fiscal”.

50 LA LEY 170366/2007 
De esta sentencia no solo sorprende que se indique que el artículo 103 Ley de Enjuiciamiento Criminal no admite interpretaciones, sino que sancione a la acusación particular con el pago de las costas por su mala fe. Sin embargo, esta asombrosa Sentencia olvida, por completo, que si la acusación particular llegó a juicio oral (según se fundamenta, por fraude de ley) lo fue no por decisión propia sino por permitírselo el Juzgado de Instrucción y la propia Sala sentenciadora al admitir su competencia para el enjuiciamiento $^{51}$. Que los Tribunales entiendan que la mala fe y la responsabilidad recae en el Letrado es otra prueba evidente de que la cuestión jurídica de fondo no solo no se resuelve con lógica, sino que se cubre con argumentos verdaderamente excesivos.

En definitiva, y por más que Sentencias como la que acabamos de citar consideren que no existe más interpretación que la suya propia, entendemos que ni por vía del artículo 268 del Código Penal se puede fundamentar una excusa absolutoria genérica para delitos distintos a los estrictamente patrimoniales ${ }^{52}$ (Título XIII, Capítulos I al IX), ni tampoco se puede eliminar, por vía del artículo 103 Ley de Enjuiciamiento Criminal, la facultad genérica de denunciar de la víctima. Cercenar el derecho de ejercitar la acción penal solo consagra una impunidad inaceptable ante conductas delictivas públicas y esto no es asumible desde perspectiva del principio de legalidad y la obligación que entraña el ejercicio del ius puniendi para el Estado, y concretamente para sus órganos jurisdiccionales.

En esta misma línea crítica se encuentra la Ilma. Audiencia Provincial de Madrid ${ }^{53}$, en su Sentencia de 20 de septiembre de 2012, cuando indica que la restricción impuesta por el artículo 103 Ley de Enjuiciamiento Criminal, aun en el caso de que no fuera objeto de la interpretación integradora que avala la nueva redacción del art. 268 del Código Penal, se está extendiendo artificialmente a otros entes jurídicos con personalidad jurídica propia y diferenciada.

De ahí que se considere que sólo a partir de una inaceptable interpretación que negara la personalidad jurídica predicable de cualquier sociedad mercantil y la fusionara con la de sus integrantes, podría asumirse que la limitación que, en su caso, afectaría (en este caso a los hermanos) también repercutiría en las sociedades en las que se integran.

La idea de levantamiento del velo no puede llevarse más allá de su genuino ámbito aplicativo. Una cosa es que mediante ese expediente se puedan neutralizar estrategias de ocultación concebidas con el fin de facilitar la comisión de hechos delictivos y otra bien distinta es que esa misma doctrina sirva para instaurar obstáculos de relevancia constitu-

51 Criterio compartido por la Audiencia Provincial de Madrid, cuando en su Sentencia 73/2018, de 2 de febrero de 2018 (LA LEY 20130/2018) afirma que tal falta de legitimación debió haberse postulado en la fase instructora o, en el peor de los casos, en el debate preliminar al juicio oral previsto en el artículo 786.2 de la Ley de Enjuiciamiento Criminal

52 Sentencias que, incluso, concluyen bien al afirmar que la cuestión civil, una vez admitida la excusa absolutoria, puede y debe ventilarse en el mismo procedimiento penal no evitan afirmaciones incorrectas como la siguiente: "apreciada la referida excusa absolutoria, no es dable si quiera entrar en el estudio de la posible comisión de un delito de coacciones...por cuanto dado el carácter, en cierto modo genérico o globalizador de este ilícito penal, el mismo resultaría siempre apreciable, según la forma de razonar de la recurrente, en presencia de aquellos delitos patrimoniales no violentos a los que resultara aplicable la excusa absolutoria, quedando así preterida la decisión del legislador relativa a excluir a los autores de los mencionados comportamientos de toda responsabilidad penal (SAP Cuenca 113/2001, de 20 de diciembre, LA LEY 230130/2001)

53 El criterio jurisprudencial de esta sentencia (junto con otras) se encuentra acogida incluso por otras Resoluciones; Sirva de ejemplo Auto de la Ilma. Audiencia Provincial de Madrid (658/2012), que, haciendo un escrupuloso análisis de la cuestión, no olvida que la formalidad o la interpretación extrapolada no puede impedir el ejercicio de la acción penal, y lo que es más importante, no puede limitar la persecución de aquellas conductas claramente delictivas. 
cional, impidiendo el ejercicio de la acción penal a quienes, por tener una personalidad jurídica propia, no resultan afectados por la relación familiar que actúa como presupuesto de la limitación que consagra el artículo 103 de la ley de Enjuiciamiento Criminal.

Pero a pesar de que encontremos ciertas sentencias que no defiendan una interpretación extensiva del artículo 103 de la Ley de Enjuiciamiento Criminal a cualquier sujeto vinculado con parientes (sociedades familiares, por ejemplo), ninguna entra a valorar la contradicción sistemática de dicho precepto con lo dispuesto en el Código Penal, de tal forma que se termina igualmente por cercenar el derecho de acción penal entre parientes.

La cuestión en la doctrina es bien distinta. Así, y en palabras de GONZÁLEZ RUS $^{54}$, no resulta claro que la excusa pueda ser aplicable a los tipos que, junto al patrimonio, toman en cuenta intereses generales, como ocurre en determinadas cualificaciones del hurto, robo con fuerza, de la estafa, la apropiación indebida o los daños; y desde luego lo que es claro es que la excusa no alcanza a los delitos que pudieran acompañar al patrimonial.

El sector que defiende la impunidad absoluta, de las sociedades familiares, olvida la personalidad propia de las personas jurídicas, extremo éste particularmente interesante cuando se trata de delitos patrimoniales cometidos en una sociedad mercantil de corte familiar; La autonomía de la persona jurídica es tan evidente en la actualidad que, desde el año 2010, y para determinados delitos, tiene responsabilidad penal plena con absoluta derogación del principio societas delinquere non potest ${ }^{55} \mathrm{y}$ con absoluta independencia de si las personas físicas autoras del delito son conocidas o no (artículo 31 ter $^{56}$ ). Debemos recordar que, por ejemplo, respecto del delito de estafa, la persona jurídica también puede ser responsable penalmente. ¿Es concebible entonces, desde el principio de legalidad penal, que la responsabilidad penal de las personas jurídicas también quede a merced de una censurable interpretación analógica de la excusa absolutoria referida solo para delitos patrimoniales y para parientes? Entendemos que la cuestión tiene un excesivo calado de fondo y cuyo debate no puede quedar cerrado a merced de criterios jurisprudenciales basados en el principio de mera oportunidad o reducción burocrática.

\section{SOLUCIÓN PROCESAL: CONDENA TRAS JUICIO ORAL, EXCLUSIÓN DE LA PENA Y PRONUNCIAMIENTO EN MATERIA CIVIL}

Ni siquiera en la práctica forense se encuentra claro el momento en el que tiene que operar la excusa absolutoria del artículo 268 del Código Penal. Así, se sostienen diversas posibilidades: a) que la aplicación de la excusa haga innecesario proseguir la

54 GONZÁLEZ RUS, JJ, Delitos contra el Patrimonio y contra... Op. Cit. P. 558

55 Y ello con carácter general, pues, como tenemos afirmado, la verdadera derogación se produce respecto del principio societas puniri non potest, pues que la persona jurídica pueda ser penada no significa que el legislador haya entendido que pueda delinquir.. (PÉREZ ARIAS, J. Sistema de atribución de responsabilidad penal a las personas jurídicas. Madrid. 2014. P. 20)

56 Establece el citado precepto que la responsabilidad penal de las personas jurídicas será exigible siempre que se constate la comisión de un delito que haya tenido que cometerse por quien ostente los cargos o funciones aludidas en el artículo anterior, aun cuando la concreta persona física responsable no haya sido individualizada o no haya sido posible dirigir el procedimiento contra ella. 
tramitación de la causa respecto a un sujeto del que se pueda afirmar, sin necesidad de enjuiciamiento, que no es penalmente responsable; b) que no existe ningún obstáculo para que, abierto el juicio oral, se pueda dictar Sentencia penal absolutoria que declara la responsabilidad civil; c) que en el caso de proseguir el proceso, la condena en costas solo comprende las derivadas del ejercicio de la acción civil; y d) que si la excusa se plantea al inicio del procedimiento y las actuaciones se archivan la responsabilidad civil se deberá reclamar en la jurisdicción competente (CORCOY BIDASOLO/MIR PUIG ${ }^{57}$ ).

Para centrar la cuestión debemos recordar que la excusa absolutoria parte, necesariamente, de un hecho típico, antijurídico y culpable. Es decir, no supone ni una causa de justificación ni un motivo de inculpabilidad ${ }^{58}$.

Por tanto, se hace necesario determinar, para reclamar la responsabilidad civil a que limita el Código Penal la actuación de la víctima, si el hecho objeto de conflicto abarca el tipo de injusto y resulta culpable. Dichas cuestiones, de naturaleza penal estricta, pueden y deben ser valoradas en el orden penal. No consideramos aplicable la posible reserva de acciones civiles en este caso, pues dándose esta es evidente que el proceso penal no tendría misión alguna para la víctima. Distinto sería que se obtuviera una sentencia de condena y se decidiera, motu proprio, acudir a la vía civil para la depuración de la responsabilidad civil, pues en este caso la sentencia penal actuaría como premisa fáctica de los hechos a dilucidar en el orden civil (efecto positivo de la cosa juzgada).

Entendemos preferible por todo ello la opción b) señalada por estos autores, esto es, se debe abrir y celebrar el juicio oral, debe dictarse sentencia de condena, con exclusión expresa de la pena, y entrar en las cuestiones civiles. Tal opción es respetuosa con el tenor literal de la norma cuando dice que "están exentos de responsabilidad criminal y sujetos únicamente a la civil...", y ello por dos razones: De un lado, porque la responsabilidad civil deviene de la comisión de un hecho típicamente antijurídico y culpable cuyo conocimiento es competencia exclusiva de los tribunales penales; y de otro, porque dicha consideración de antijurídico y culpable solo puede ser conocido tras una valoración de la prueba en un proceso penal. Otra opción nos abocaría a una distorsión de las reglas de división de los órdenes jurisdiccionales, incluyendo las que establecen la preferencia absoluta del orden penal cuando estemos ante hechos con naturaleza criminal ${ }^{59}$.

57 CORCOY BIDASOLO/MIR PUIG: Comentarios al Código Penal. Valencia. 2011. P. 595

58 Es precisamente esta particularidad la que hizo superar la concepción tripartita del Delito; Según esta concepción la punibilidad suponía un presupuesto que hacía el razonamiento simplista: Delito es todo hecho punible. Sin embargo, y como señalan COBO DEL ROSAL/VIVES ANTÓN la referencia a punible, o si se quiere, a la punibilidad, a la conminación penal, en la noción de delito, se presenta, por tanto, como una exigencia lógica insoslayable: no toda conducta típica es punible; no toda conducta antijurídica es punible; no toda conducta culpable, que sí es punible, será castigada, pues lo será solo si así se expresa y concretamente se determina. Punible y punibilidad no hacen más que fijar una referencia lógica, y como consecuencia jurídica necesaria para la noción de delito, de modo que, conforme se ha expuesto, un delito sin punibilidad, un delito no punible, carece de sentido y en rigor no existe y, esto, no obstante, un delito sin pena, no penado, es algo absolutamente real y lógico, de acuerdo con nuestra legislación vigente (COBO DEL ROSAL/VIVES ANTÓN. Derecho Penal. Parte General. Valencia. 1991. P. 201).

59 Como sostuvo COBO DEL ROSAL, en materia penal, que no tiene, ni se debe tener, un componente demagógico, lo que no está claramente justificado, sencillamente, hay que atacarlo si deseamos mantener, real y no hipócritamente, la vigencia del viejo principio de libertad formulado por primera vez por los revolucionarios liberales franceses de la "pena necesaria", que tan ditirámbica y neciamente se pregona ahora por doquier, justo para no cumplirlo (COBO DEL ROSAL, M, Sobre el ejercicio de acciones penales entre parientes... Op. Cit. P.557) 


\section{EXTRAPOLACIÓN DEL CRITERIO A OTRAS EXCUSAS ABSOLUTORIAS CONTENIDAS EN EL CÓDIGO PENAL}

Por último, es preciso comprobar si esta tendencia -jurisprudencial- ampliadora del ámbito de aplicación del artículo 268 del Código Penal, basada en la analogía in bonam partem, hace permisible, per se, su extrapolación a otras excusas absolutorias contenidas en este cuerpo normativo

Para ello, hemos de justificar si esta interpretación extensiva del artículo 268 del Código Penal se fundamenta, en realidad, en una analogía in bonam partem (como se sostiene por esta corriente jurisprudencial), o simplemente, y pese a lo que se diga, tal ampliación interpretativa reside, en exclusiva, en la protección del valor "familia" (con cobertura en el artículo 103 de la Ley de Enjuiciamiento Criminal).

Si estuviéramos en el segundo caso, la conclusión parece clara: No habría más interpretación extensiva que aquella que se base en el ámbito familiar y en conflictos de índole económica. Y ello, al entender que la cuestión -erróneamente interpretada- queda cerrada y reafirmada con el artículo 103 de la Ley de Enjuiciamiento Criminal. No es necesario reiterar lo manifestado más arriba, pero sí debemos recordar que esta interpretación se sostiene en un razonamiento circular y autopoiético. Lo correcto, ante semejante conflicto normativo, es valorar que una de las leyes en cuestión no puede tener ámbito aplicativo. En este caso, y por lo manifestado, entendemos que el artículo 103 de la Ley de Enjuiciamiento Criminal ha perdido por completo su vigencia.

Sin embargo, si los Tribunales se apoyan en el primero de los fundamentos (esto es, en la analogía in bonam partem), entendemos que no debería haber obstáculo para considerar, a su vez, que las excusas absolutorias que se encuentran a lo largo del Libro II puedan ser aplicadas a casos de naturaleza similar para las que están previstas.

Es el ejemplo del antiguo artículo 308 (delito fraude de subvenciones estatales), para el que se preveía una excusa absolutoria en caso de regularización, y del artículo 309 (Delito de fraude de subvenciones comunitarias), para el que no existe tal posibilidad normativa de exclusión ${ }^{60}$. Nada debe obstaculizar una interpretación extensiva (a la vista de lo que se realiza jurisprudencialmente con el artículo $268 \mathrm{CP}$ ), teniendo en cuenta que esta aplicación analógica no afectaría al bien jurídico (europeo) pues queda igualmente reparado (tras la regularización) por más que estemos ante una Hacienda no estatal. La distinta ubicación de ambos delitos (fraude de subvenciones estatales, en el artículo 308 CP y fraude de subvenciones comunitarias, en el artículo $309 \mathrm{CP}$ ) obedece a cuestiones de mera política legislativa ya que ambos delitos comparten los elementos típicos (salvo la cuantía objetiva).

60 Hipótesis que analizamos respecto de aquellos hechos pendientes de enjuiciamiento pero que datan de fechas anteriores al año 2012. Como es sobradamente conocido, tras la reforma operada mediante L.O. 7/2012, de 27 de diciembre, por la que se modifica la L.O. 10/1995, de 23 de noviembre, del Código Penal en materia de transparencia y lucha contra el fraude fiscal y en la Seguridad Social, las excusas absolutorias en materia tributaria penal han sido profundamente modificadas. (véase para mayor detalle PÉREZ ARIAS, J. Delitos contra la Hacienda Pública y contra la Seguridad Social y delitos contra los derechos de los trabajadores y de ciudadanos extranjeros, en Estudios sobre el Código Penal reformado (Leyes Orgánicas 1/2015 y 2/2015), MORILLAS CUEVA (Dir.), Madrid. 2015. PP. 691-718) 
En definitiva, y como afirma MORALES PRATS ${ }^{61}$, la conducta típica del artículo 309 se describe de forma prácticamente idéntica a la conducta recogida en el artículo 308 (fraude de subvenciones), de manera que en este caso se puede reproducir una buena parte de lo que se dice allí. Lógicamente, varía el límite mínimo de la cantidad exigida a los fondos comunitarios para que la conducta defraudatoria tenga rango de delito: es necesario que alcance un valor superior a 50.000 euros.

Si lo que se pretende es realizar una interpretación a favor del reo, necesariamente se debe partir de un análisis de fondo en cada una de las figuras delictivas en debate; no hacerlo en estos casos, y sí en el supuesto de conflictos familiares, supondría una simplificación buscada de propósito sin mayor motivo que la discrecionalidad excesiva de los Juzgados o Tribunales. Algo que, de manera indiscutida, supone no solo una vulneración de la tutela judicial efectiva de la víctima y del principio de igualdad, sino una inseguridad jurídica de difícil asunción en un sistema jurídico como el nuestro.

En definitiva, por valiosas que pudieran ser las razones de concordia familiar, que seguramente pesan en la concesión de la excusa absolutoria, ya que las de la comunidad familiar son insostenibles al permitirse el ejercicio de la acción civil, la impunidad pura y neta resulta un tanto excesiva. Todavía sería explicable si se refiere a sustracciones o daños de escasa consideración y a estrictos supuestos de efectiva convivencia..., pero estimar acto excusable el de un hijo de familia, o el de otro miembro, por allegado que fuera (iy no digamos nada de los cuñados!), que deja en la ruina a otro o a toda ella, forzando, por ejemplo, la caja de caudales, es cosa que rebasa el respeto debido a las convenciones más fundadas (QUINTERO RIPOLLÉS ${ }^{62}$ ).

\section{BIBLIOGRAFÍA}

Álvarez VizcaYA, M. La excusa absolutoria de los delitos patrimoniales: artículo 268 del CP, en Estudios jurídicos en memoria de José María Lidón. Bilbao. 2002.

Bajo Fernández, M. El parentesco en Derecho Penal. Barcelona. 1973.

Benítez Ortúzar, I. F. En Delitos contra el Patrimonio y contra el orden socioeconómico (I), en Sistema de Derecho Penal Español. Parte Especial (Dir. Morillas Cueva). Madrid. 2016.

Сово Del Rosal, N. Sobre el ejercicio de acciones penales entre parientes en los delitos contra el patrimonio y el orden socioeconómico. Cuadernos de política criminal. Madrid. 2002.

Corcoy Bidasolo/Mir Puig. Comentarios al Código Penal. Valencia. 2011.

Córdoba Roda, J. El parentesco como circunstancia mixta de modificación de la responsabilidad penal. Anuario de derecho penal y ciencias penales, Tomo 20, Fasc/Mes 1-2, 1967.

Domingo Monforte, J. La Administración desleal y la excusa absolutoria de parentesco. Diario La Ley, No 9158, Sección Tribuna, 14 de marzo de 2018, Editorial Wolters Kluwer.

González Rus, J. J. En Delitos contra el Patrimonio y contra el orden socioeconómico (I), en Sistema de Derecho Penal Español. Parte Especial (Coord. Morillas Cueva). Madrid. 2011.

Luzón CÁNovas, A. LA ACCION POPULAR. ANALISIS COMPARATIVO CON LA ACUSACION PARTICULAR. Diario La Ley, N. o 5483, Año XXIII, 15 de febrero de 2002, Ref. D-51, pág. 1796, tomo 2, Editorial LA LEY.

61 MORALES PRATS, F. Delitos contra la Hacienda Pública y contra la Seguridad Social. Fundación para la Universitat Oberta de Catalunya. P. 36.

62 QUINTERO RIPOLLÉS, A. Comentarios al Código Penal. 2a Ed. Madrid. 1966. P. 1060 
Mestre Delgado, E. Delitos contra el patrimonio y contra el orden socioeconómico, Delitos. La parte especial del Derecho Penal (Coord. LAMARCA PÉREZ, C). Madrid. 2016.

Morales Prats, F. Delitos contra la Hacienda Pública y contra la Seguridad Social. Fundación para la Universitat Oberta de Catalunya.

NAVARRO FRÍAS. En ROMEO CASABONA/ NAVARRO FRÍAS, en Delitos contra el patrimonio y el orden socioeconómico II. Defraudaciones, insolvencias punibles, alteración de precios en concursos y subastas públicas y daños, Derecho penal. Parte especial. Granada. 2016.

Navarrete Urieta, J. M. El encubrimiento entre parientes (artículo 18 del Código Penal). Anuario de derecho penal y ciencias penales, Tomo 13, Fasc/Mes 2, 1960.

Orts Berenguer/ González Cussac. En Causas específicas de exclusión de la pena, Compendio de Derecho Penal. Parte General. Valencia. 2014.

PÉrez Arias, J. Delitos contra la Hacienda Pública y contra la Seguridad Social y delitos contra los derechos de los trabajadores y de ciudadanos extranjeros, en Estudios sobre el Código Penal reformado (Leyes Orgánicas 1/2015 y 2/2015), MORILLAS CUEVA (Dir.), Madrid. 2015.

PÉrez Arias, J. Sistema de atribución de responsabilidad penal a las personas jurídicas. Madrid. 2014.

Peris RierA, J. Derecho penal económico y Código Penal español de 1995: Aproximación a la sistemática de los delitos contra la economía. en Revista de Derecho penal y Procesal penal, N 3/2006. Buenos Aires. 2006.

Quintero Ripollés, A. Comentarios al Código Penal. 2a Ed. Madrid. 1966.

Rodríguez Ramos, L. Código Penal concordado con jurisprudencia sistematizada y leyes penales especiales y complementarias. La Ley. Madrid. 2007.

Sáinz Cantero. En Lecciones de Derecho Penal. Parte General. Barcelona. 1990.

Serrano Gómez, A. Derecho Penal. Parte Especial, Madrid, 2000.

Silva SÁnchez, J. Hermanos, pero no primos. Los delitos patrimoniales y el alcance de la excusa absolutoria del artículo 268 del Código Penal. Una crítica a la doctrina del Tribunal Supremo, Diario La Ley, Sección Doctrina, 2001, Ref. D-126, Tomo 4. 2001.

\section{JURISPRUDENCIA}

TRIBUNAL CONSTITUCIONAL: SSTC 50/1982, de 15 de julio (LA LEY 87-TC/1982), 107/1994, de 11 de abril (LA LEY 13129/1994), 139/2000, de 29 de mayo (LA LEY 8966/2000), 151/2001, de 2 de julio (LA LEY 5046/2001), 162/2001, de 5 de Julio (LA LEY 6999/2001), 173/2002, de 9 de octubre (LA LEY 679/2003).

TRIBUNAL SUPREMO: STS 18/11/1878, 16/3/1909, 28/9/1927, 6/4/1954, 25/1/1955, 22/5/1956, 25/4/1963, 14/5/1963, 27/1/1967, 24/2/1968, 15/3/1969, 10/11/1969, 23/1/1970, 2/5/1972 , 10/06/1972, 21/2/1975, 26/2/1975; 334/2003, 5 de marzo (LA LEY 1869/2003); STS 42/2006, de 27 de enero de 2006 (LA LEY 10927/2006); STS 361/2007, de 24 de abril (LA LEY 17325/2007); STS 834/2007, de 22 de octubre (LA LEY 170366/2007); STS 933/2010, de 22 de octubre (LA LEY 203317/2010); Sentencia número 83/2010, de 11 de febrero (LA LEY 3126/2010):

AUDIENCIAS PROVINCIALES: Almería. Auto de 24 de septiembre de 2015; Burgos. SAP 360/2013, de 3 de septiembre (LA LEY 136450/2013); Cuenca. SAP Cuenca 113/2001 (LA LEY 230130/2001); Les Illes Balears SAP 111/2017, de 22 de diciembre de 2017 (LA LEY 231992/2017); Madrid. SAP Madrid, de 20 de septiembre de 2012; AAP Madrid 658/2012; SAP Madrid, 73/2018, de 2 de febrero de 2018 (LA LEY 20130/2018); Valencia. SAP, 237/2017, de 7 de abril de 2017 (LA LEY 68044/2017); Zaragoza. SAP 18/2016, de 25 de enero (ROJ: SAP Z 160/2016); 